\title{
INTELIGÊNCIA E PSYKHÉ: A EPISTEMOLOGIA DE PLATÃO
}

Rúbens Garcia Nunes Sobrinho*

\begin{abstract}
RESUMO
A questão do conhecimento, em Platão, representa uma inflexão radical em relação à investigação levada a cabo pelos filósofos présocráticos. A hipótese das Formas inteligíveis inaugura um procedimento filosófico baseado em princípios de inteligibilidade prévios aos fenômenos que articulam um princípio de economia explanatório válido para todo o kósmos. O postulado fundamental que estabelece a preexistência de um número preciso de princípios em relação à physis permite que Platão fundamente as questões éticas a partir de sua nova epistemologia que, por sua vez, é fundada na causalidade axiomática das Formas.
\end{abstract}

PALAVRAS -CHAVE: Conhecimento. Inteligência. Princípios.

\begin{abstract}
The question of knowledge, in Plato, represents a radical inflection towards the investigation taken by presocratics philosophers. The hypothesis of the intelligible Forms starts a philosophical procedure based on principles of intelligibility previous to phenomena wich articulate an explanatory principle of economy valid for all around the kósmos. The fundamental postulate that establish the preexistence of an accurate number of principles related to physis, allows Plato to base the ethical phenomena from his new epistemology which is founded on axiomatic causality of Forms.
\end{abstract}

* Doutorando em Filosofia na Universidade Federal de Minas Gerais - CNPq.

Educ. e Filos., Uberlândia, v. 21, n. 42, p. 89-117, jul./dez. 2007. 
KEYWORDS: Knowledge. Intelligence. Principles.

\section{Introdução}

O escopo desse estudo é esboçar as articulações pelas quais se estabelece, nos diálogos de Platão, um fulcro epistêmico que, em oposição à filosofia dos pré-socráticos, coloca princípios de inteligibilidade como condição de possibilidade do conhecimento. Como observa Henri Joly (1974, p. 141), "têm-se freqüentemente reconhecido que, para Platão, toda ciência é ciência de um objeto". Não obstante, a ciência, em Platão, só se constitui e se define mediatamente através da linguagem matemática, das figuras geométricas e dos procedimentos de construção que, em última instância, derivam de princípios teóricos que constituem o organon das técnicas científicas.

Para que seja demonstrado que a fundamentação da epistéme se estabelece a partir de princípios de inteligibilidade que dão conta dos fenômenos, proceder-se-á, aqui, a uma investigação da epistemologia do Fédon, o diálogo no qual Platão, pela primeira vez, expõe de maneira positiva uma doutrina do conhecimento explicitada em termos de princípios, em contraposição ao método empirista adotado pelos filósofos pré-socráticos. Em seguida, serão investigadas as escalas de conhecimentos explicitadas na analogia da "linha" na República, a demiurgia no Timeu, e, finalmente, a questão da primazia da psykhé em relação a empeiria esboçada no livro X das Leis. Dessa perspectiva e estratégia de abordagem resultará a evidência de que o conhecimento e o uso das construções obtidas pelo conhecimento, em Platão, exigem a determinação de princípios de inteligibilidade que lhes constituem a condição prévia.

\section{I - A epistemologia do fédon}

A discussão travada no Fédon constitui a narrativa de uma morte. Mas a morte enfocada aqui não é uma morte qualquer: é a morte de Sócrates, o melhor, o mais sensato e o mais justo dos

Educ. e Filos., Uberlândia, v. 21, n. 42, p. 89-117, jul./dez. 2007. 
homens (118a). A imparidade do homem e a sua exemplaridade implicam uma reflexão sobre a própria possibilidade de se falar filosoficamente sobre a morte e sobre a possibilidade de se pensar a imortalidade com o rigor argumentativo que caracteriza a dialética, o modo de investigação propriamente filosófico que é, ao mesmo tempo, a ciência superior. Essa investigação sobre a imortalidade coloca em questão a própria reflexão filosófica e o modo como o saber filosófico se instaura. A reflexão sobre a imortalidade traz, em seu bojo, as questões de fundo da instauração do conhecimento e do método peculiar à investigação filosófica.

A justificação da filosofia como modo de vida exige um discurso racional que deve dar conta de sua própria validade como démarche de aquisição do conhecimento. Toda a encenação dramática do início do diálogo gira em torno da oposição entre a percepção sensível e o pensamento, como origem constitutiva do conhecimento. A distinção entre o corpo e a alma, condição da imortalidade, emerge a partir de um estoque de crenças míticas compartilhadas entre os circunstantes que configuram as premissas que deverão passar pelo crivo do exame argumentativo (BRISSON, 1995, p. 24, 25). Tal distinção engendra a separação subjacente entre dois modos de conhecimento que giram em torno de centros incongruentes: o da percepção e o do pensamento puro.

E com referência à aquisição do conhecimento? O corpo constitui ou não constitui obstáculo, quando chamado para participar da pesquisa? O que digo é o seguinte: a vista e o ouvido asseguram aos homens alguma verdade? Ou será certo o que os poetas não se cansam de afirmar que nada vemos nem ouvimos com exatidão...?

Perfeitamente, respondeu.

Então, perguntou, quando é que a alma atinge a verdade ? É fora de dúvida que, desde o momento em que tenta investigar algo na companhia do corpo, vê-se lograda por ele.

Tens razão.

E não é no pensamento - se tiver de ser de algum modo que algo da realidade se lhe patenteia? (Fédon, 65 a-c)

Educ. e Filos., Uberlândia, v. 21, n. 42, p. 89-117, jul./dez. 2007 
O conhecimento oriundo dos sentidos é inexato, pois a sensação é inconstante e a percepção não tem acurácia. O alvo do conhecimento aponta para as "coisas em si mesmas" ou para as "essências" (65e), e somente a reflexão "nela mesma e sem mistura" (66a), independente da mediação da sensação, pode ser intermediária da apreensão dessas realidades "nelas mesmas". Platão se vale de um acervo de crenças míticas ligadas a uma tradição órfico-pitagórica e às seitas de mistério, e empreende uma transposição de noções originariamente místicas para uma filosofia centrada na reflexão depurada da empeiría (JOLY, 1974). O materialismo teórico que identifica a origem do conhecimento com elementos materiais decorre, em última instância, da identificação entre psykhé e sôma. A distinção da reflexão como apanágio da psykhé implica que o conhecimento da ousia não pode ser obtido mediante os sentidos ou no sôma.

A ousia demarca o âmbito de uma postulação que funda os princípios de cognoscibilidade que ditam as condições de possibilidade do conhecimento. A ousia designa "o que é" e remete para o ser no mais alto grau (DIXSAUT, 1991, p. 479 ss.). Ela não resulta de uma abstração e não é um gênero delimitado por propriedades comuns a uma multiplicidade. A ousia é constitutiva do ser e o determina. A sua apreensão exige uma separação dos elementos materiais e corporais que é congruente com a independência do pensamento puro da psykhé pensante. Um ser é determinado pelo pensamento que o examina e este, por sua vez, é determinado pela ousia. Ela engendra o pensamento ao mesmo tempo em que é engendrada pela reflexão e constitui o modo de ser próprio da dialética. Essa dupla geração ocorre no âmbito de um logos inextricável da psykhé.

Se a sede da cognoscibilidade está na psykhé, então ela é condição da inteligibilidade de todas as coisas. Ao aventar o "antigo logos" das seitas de mistério, Platão promove uma racionalização e uma nova significação nas noções de iniciação e purificação. $O$ verdadeiro iniciado não é mais o antigo mestre de sabedoria, mas o filósofo cujo "exercício de morte", meleté thânatou, consiste em estabelecer o primado da reflexão pura sobre o conhecimento sensível.

Educ. e Filos., Uberlândia, v. 21, n. 42, p. 89-117, jul./dez. 2007 
O filósofo é um amante do pensamento puro (68a) e o desejo é o princípio de ação que o motiva a "aprender corretamente" (67b). A purificação enseja a aparição de um novo tipo de homem: o "homem teórico" (JOLY, 1974, p. 64), que erige uma nova epistemologia orientada para uma redefinição matemática da purificação. O exercício filosófico consiste em separar o pensamento de toda mistura com o que é corporal ou material e essa separação representa a desvinculação da psykhé com o corpo. Assim, a nova epistemologia calcada no pensamento puro, engloba, em uma mesma definição, o morrer, o filosofar e o pensar.

A phrónesis - reflexão purificada que caracteriza a psykhé e a inteligência - implica também um novo ethos cujas bases são assentadas em valores absolutos universais. A valoração de toda virtude só pode ser estabelecida em relação a um referencial absoluto que é modelo e princípio de ação. Uma virtude só pode ser adquirida mediante a única instância própria para atribuir valor: a phrónesis (69a-c). Sem a reflexão purificada não há medida para a valoração dos princípios de ação e toda virtude torna-se correlativa às demais, trocando-se e falseando-se como se tratasse de moedas falsas. $O$ único padrão de troca legítimo que permite a aquisição e a valoração de todos os princípios de ação é a reflexão pura (Fédon, 69b-c).

O que faz o valor do filósofo é o valor de um referencial absoluto a partir do qual definem-se o saber, o conhecimento e as virtudes. O conhecimento fundado nas apercepções da experiência sensível é somente relativo, pois toda sensação é contingente e incerta. Uma epistemologia que se baseia apenas nas sensações estabelece correlações falseadas mediante as interações horizontais das coisas percebidas. Somente a remissão a uma instância superior, referência absoluta, pode conferir, numa relação vertical, significação ao conhecimento e valoração aos princípios de ação prática.

A concepção materialista de uma psykhé constituída por partículas materiais e passível de dispersão, como fumo, transmitida pelos acousmáticos ligados a Filolau de Crotona (KHAN, 2001, p. 23 ss.), traz na sua esteira uma epistemologia 
empirista que parte de elementos físicos primordiais, característica do quadro mental moldado pelos filósofos pré-socráticos. A nova epistemologia platônica, em contrapartida, afirma o primado de uma realidade - a psykhé, que se identifica com a sede do pensamento - em relação aos elementos materiais propugnados pelos fisiólogos ${ }^{1}$. A existência independente dessa realidade garante a possibilidade de que o conhecimento seja um constructum regrado segundo o conhecimento prévio de um paradigma. No Fédon, os argumentos aduzidos em prol da imortalidade entretecem os princípios de inteligibilidade que formam o arcabouço dessa nova epistemologia².

O primeiro argumento em favor da imortalidade, o argumento dos opostos, explicita os princípios subjacentes às noções de transformação e processos temporais de mudança. Todo processo consiste numa sucessão, um movimento no devir cujos pontos ou estados só podem definir-se correlativamente mediante seus opostos. A correspondência entre a alternância de opostos com os processos de mudança implica a reversibilidade de todo processo

1 Maura Iglesias, a partir da tese clássica de Harold Cherniss, demonstra que o princípio de economia que está na base da Filosofia platônica pressupõe a unificação das qualidades psíquicas numa instância independente, a alma: que promoveria a unificação das questões éticas com a epistemologia a partir da fundamentação ontológica ensejada pelas Formas (IGLÉSIAS, 1998, p. 13-58).

2 Carl Huffman demonstra que Filolau de Crotona inaugura em sua filosofia, no século $\mathrm{V}$ a.C., o método das hipóteses e emprega o termo arkhé no sentido de uma origem preexistente (hypárlhein) ao kósmos. As arkhai são princípios explanatórios prévios que funcionam como postulados fundamentais como os axiomas geométricos. A grande inflexão promovida por Filolau em relação ao contexto dos pré-socráticos do quinto século reside na adoção de um princípio de economia na elaboração de sua explicação do kósmos. "Filolau explicitamente identifica as arkhai como ponto inicial mínimo ou princípios requeridos para explicar os fenômenos". Seu método, em vez de partir dos fenômenos, recorre a um número mínimo de princípios preexistentes como recurso explanatório que dê conta dos fenômenos. Por essa razão, Filolau afirma que a Geometria é a "cidade mãe" e arkhé das outras ciências (mathémata). O método das hipóteses de Filolau é apropriado e desenvolvido por Platão no estabelecimento de sua hipótese das Formas e da axiomática como elemento fundamental da dialética de suas obras da maturidade. (HUFFMAN, 1998, p. 78-92).

Educ. e Filos., Uberlândia, v. 21, n. 42, p. 89-117, jul./dez. 2007. 
e o axioma de que as interações da natureza são simétricas. Todo devir pressupõe a passagem e o movimento por estados segundo uma correlação de simetria, de anterioridade e posterioridade. Uma vez que há dois termos contrários - cuja contrariedade reside na relação instaurada pelo devir - devem existir, infalivelmente, dois movimentos de devir, indo de um termo ao outro em sentidos opostos e simétricos (DIXSAUT, 1991, p. 90). Equivalência e simetria nos processos de mudança constituem as condições para o estabelecimento de relações entre as coisas. Toda mudança da physis é um devir cíclico em que cada estado é correlativo a outro que lhe seja simétrico. Toda gênese de um contrário implica uma passagem de um estado a outro. Um contrário nada mais é que um momento isolado de um devir contínuo que, por ser cíclico, pressupõe um outro estado oposto correlativo ao primeiro. Momentos isolados do devir só podem ser definidos mediante a correlação com os opostos que lhe sirvam de referência.

Opostos são modos de ser extremos, um em relação ao outro, isolados de um processo que é um movimento cíclico único e contínuo. Se os opostos são dois estados extremos, geram-se reciprocamente e, então, entre um e outro há dois processos de geração. Sócrates considera que entre os opostos "dormir" e "estar desperto" ocorrem dois processos também opostos, a saber: o "acordar" e o "adormecer". Por outro lado, o estado de estar vivo e o de estar morto, dois opostos, geram-se reciprocamente de forma que o estar vivo provém do estar morto e vice-versa. Por conseguinte, os seres vivos e as pessoas provêm do estado de estar morto.

Mas, para que o argumento se sustente, é preciso mostrar que a geração de um estado oposto a outro é correlativa à geração de um processo oposto a partir de outro. Um dos processos revelados a partir do par de opostos "estar vivo" e "estar morto" é, por si mesmo, evidente - o morrer - e para que a natureza não fique "manca" (71e) é preciso a anteposição de um processo oposto análogo, qual seja, reviver. Se existe alguma coisa tal como "reviver", esta deve ser o processo pelo qual os vivos provêm dos mortos. Todo o argumento está fundamentado na hipótese axiomática de

Educ. e Filos., Uberlândia, v. 21, n. 42, p. 89-117, jul./dez. 2007. 
que a physis não pode ficar "manca", hipótese sem a qual, não há contrapartida ao processo de morrer e o oposto que o balanceia é negado. Esse postulado, importantíssimo, assume a natureza como orgânica, ela é viva assim como um animal é vivo e em decorrência disso, por uma concepção extremamente fecunda, propõe o conceito de simetria como fundamento de todos os processos que envolvem opostos. Uma coisa é simétrica quando após ser submetida a uma determinada operação ou processo permanece a mesma; isso significa que é uma propriedade intrínseca da physis o fato de que há um princípio que remanesce constante em processos de mudança.

O processo correlato à morte - reviver - não se refere apenas à passagem da morte para a vida, mas implica o processo de viver novamente e essa geração só é possível se algo permanece constante no processo, uma vez que ele é circunscrito numa relação simétrica. A simetria da natureza em relação aos opostos implica a alma como remanescente da geração recíproca entre morrer e reviver. A simetria é a condição pela qual as relações entre interações que ocorrem na temporalidade podem ser compreendidas e tal condição reforça o primado da psykhé no estabelecimento das definições constituintes do saber.

O segundo argumento em favor da imortalidade amplia os princípios de cognoscibilidade da nova epistemologia platônica. O chamado "argumento da reminiscência" trata do modo como o conhecimento é adquirido e demonstra que o conhecimento começa com a percepção, mas só se estabelece na concepção e na inteligência.

Para que haja uma reminiscência é preciso estabelecer duas condições que são, simultaneamente, condições para a primazia dos princípios de inteligibilidade em relação às sensações: a relação de anterioridade e posterioridade temporais - um saber adquirido em um momento anterior é necessário para que algo seja lembrado; e a passagem da percepção sensível para a concepção (73c).

$\mathrm{O}$ argumento reproduz as conclusões e a transposição da passagem da percepção para a concepção operada no Ménon (82b - 85d). Na rememoração deve haver o esforço da investigação e o

Educ. e Filos., Uberlândia, v. 21, n. 42, p. 89-117, jul./dez. 2007. 
reconhecimento prévio da própria ignorância para suscitar o desejo de saber, além da boa condução pela interrogação. O exemplo geométrico do Ménon evidencia a passagem do plano da figuração, do despojamento gradual da percepção da figura desenhada, para a idealidade matemática apreensível apenas pelo pensamento. A desmaterialização das imagens e a dessensibilização das noções permitem a distinção dos princípios de inteligibilidade que demarcam o primado do pensamento puro no constructum do conhecimento. O despojamento da dependência sensorial faz com que a imagem torne-se figuração que remete para as noções geométricas rigorosas (JOLY, 1994, p. 195). A figuração engendra a apreensão das "coisas em si mesmas" e, por essa razão, a geometria é gerativa de princípios que ela institui como hipóteses de um raciocínio matemático que tem como base subjacente uma remissão que parte de um conhecimento de origem sensível para um conhecimento de outra ordem: a concepção de idealidades que são independentes da percepção.

No Fédon, o conhecimento começa com a sensação, mas apenas como recurso que opera a reportação para as noções da inteligência. Os exemplos listados no diálogo, que associam a imagem com um modelo original, evidenciam que a reminiscência requer a dupla mediação do desejo e da reflexão (DIXSAUT, 1991, p. 98). A imperfeição e a carência da imagem em relação ao original, e a correspondente passagem da percepção da imagem para a concepção do modelo relembrado, patenteiam o fato de que o princípio de ação, que é aspiração ao saber, é o desejo. A aspiração à completude e perfeição fornecidas pelas noções do plano do pensamento puro desencadeia o processo do conhecimento e o esforço necessário para a correta derivação das conseqüências das hipóteses axiomáticas. Dessa maneira, a sensação constitui uma condição necessária para o conhecimento, mas não uma condição suficiente.

-É preciso, portanto, que tenhamos conhecido a igualdade antes do tempo em que, vendo pela primeira vez objetos iguais, observamos que todos eles se esforçavam por alcançá-la, porém lhe eram inferiores. (Fédon, 75a) 
O princípio de cognoscibilidade é um conhecimento prévio àquele oriundo das sensações. Ele é o paradigma que regula e dá a medida da perfeição ideal em relação às imagens fornecidas pela percepção. Mas a sensação, em vez de obstáculo ao conhecimento, é condição necessária, assim como a vida corporal é condição necessária para o aprendizado e para a reminiscência. $\mathrm{O}$ desejo concilia os afetos e as sensações com a reflexão de modo a fornecer a dimensão da carência da imagem e operar a passagem para a concepção da noção. O processo de figuração geométrica, ou seja, a transposição da imagem para o paradigma inteligível, exige a apresentação da imagem aos sentidos. É necessário um ponto de partida que dispare o processo de conhecimento, mas não é a sensação em si mesma que dispara esse processo. O conhecimento inicia-se com a reflexão, cuja determinação é prévia à sensação, da carência e deficiência da imagem fornecida pela sensação em relação a um paradigma. A aquilatação da imperfeição só é factível pela regulação prévia operada mediante o conhecimento do modelo paradigmático. Uma percepção em si mesma não implica nenhuma associação inevitável com uma noção. Essa associação só ocorre pela consciência da dissimilitude e da imperfeição, isso significa que as noções da inteligência possuem uma prioridade epistemológica e ontológica em relação à percepção. As "coisas em si mesmas" não podem ser abstraídas das sensações: sua prioridade é a condição de possibilidade da própria percepção. Assim como uma figura, intermediária entre a percepção e a concepção, é apenas uma cifra do inteligível, assim também todo o plano do sensível é imagem de uma realidade verdadeira e paradigmática. O que a psykhé traz em seu âmago não são as Formas ou idéias inatas, mas um conhecimento que regra a aquisição de todos os saberes. A ocasião para a passagem só ocorre em função de uma psykhé que deseja e aspira ascender a uma realidade superior. Por essa razão, a epistemologia do Fédon não é fundada num apriorismo transcendental. Apenas o desejo pode vincular a percepção à inteligência. Mas ao fazê-lo, reforça o conhecimento como construção e a psykhé como criadora.

A concepção de um processo de conhecimento cujas noções

Educ. e Filos., Uberlândia, v. 21, n. 42, p. 89-117, jul./dez. 2007. 
são abstrações de percepções ou cuja base é inteiramente material é incompatível com o argumento do conhecimento do criador porque os princípios de toda criação seriam, nesse caso, extrínsecos à inteligência. A concepção materialista da alma é incompatível com a imortalidade e com princípios universais absolutos e invariáveis. Se tudo é composto por princípios materiais, então a alma está sujeita a se dispersar. O argumento da "afinidade" estabelece a semelhança da alma com as Formas invariáveis e ressalta o fato de que a natureza distintiva da psykhé é a escolha, a autoria e a determinação de sua própria natureza.

As essências caracterizadas pela univocidade da forma fazem parte da classe de seres invariáveis. As coisas múltiplas são variáveis. As essências invariáveis são invisíveis e apreensíveis mediante o pensamento, ao passo que as coisas compostas e variáveis são perceptíveis pelos sentidos (78d-79a). O corpo, visível, é mais aparentado com as coisas múltiplas que estão em permanente mudança. A alma é mais semelhante com o que é invisível do que o corpo, embora não seja isenta de mudanças. A sua natureza depende dos objetos aos quais aplica o seu desejo. Se ela se volta para o devir e a inconstância, torna-se inconstante e variável segundo o modo como usa seus afetos. Se os objetos de sua escolha, o alvo de sua faculdade de reflexão, forem coisas que permanecem sempre as mesmas, então ela se torna semelhante ao que é em si mesmo e ao divino. A semelhança da psykhé com o que é em si mesmo depende de sua atividade. A alma não é indissolúvel por natureza como as Formas, pois é passível de mudança e, por essa razão, a alma não pertence nem à classe das coisas compostas, nem à classe das coisas simples. Por determinar sua natureza segundo o objeto de sua escolha, a alma nem é sujeita à dispersão, nem pertence à classe dos seres que excluem essa possibilidade. Ela pode ser continuamente variável, como permanecer a mesma, dependendo de seu envolvimento com o corpo e com o exercício filosófico. Mas em nenhum momento o argumento estabelece a assertiva de que a alma é simples e tampouco sustenta a imortalidade na simplicidade (DIXSAUT, 1991, p. 110). O mal maior para a alma é tomar as sensações como única realidade $\mathrm{e}$ 
perverter-se pelo apetite (83d). Isso significa que o estado de perversão é equivalente à desrazão, ou falta completa do exercício do raciocínio, é o estado em que perceber e sentir é tudo o que se pode saber, o estado em que a alma só pode "sofrer" afecções e nada pode criar, pois não tem a inteligência ativa da reflexão. A peculiaridade única da natureza da alma decorre da dynamis que ela possui de ser a autora e criadora de si mesma segundo as determinações do objeto de sua escolha.

A epistemologia do Fédon se desenvolve mais completamente na investigação sobre as causas da geração e corrupção de todas as coisas. A busca pelas causas do devir representa uma tentativa de ultrapassar a sua dimensão com a busca da causa "do que é" (96a). No início de sua carreira intelectual, Sócrates conduz essa investigação à maneira dos fisiólogos e tenta explicar os fenômenos biológicos a partir dos fenômenos físicos e os fenômenos psicológicos a partir dos fenômenos biológicos. As tentativas de se encontrar as causas primeiras de todas as mudanças em elementos materiais derivam do duplo postulado da homogeneidade e da continuidade de todos os fenômenos. Esse duplo postulado elimina as diferenças entre os fenômenos, notadamente a diferença entre sentir e saber. A concepção de uma univocidade da physis leva à concepção de que explicar é engendrar e engendrar do inferior para o superior, do simples ao complexo o que, por sua vez, direciona a investigação da causa para a razão da emergência do superior. As investigações dos fisiólogos buscavam uma explicação mecanicista do mundo em termos de princípios materiais e tentavam encontrar as causas (aitía) no campo das sensações (aistetá). A primeira tentativa de se encontrar as causas explicativas do devir parte do plano das coisas sensíveis e referencia o complexo ao mais simples pela noção de engendramento. Trata-se de um modo empirista de explicação que faz girar o conhecimento em torno do objeto. O plano das coisas sensíveis é explicado por elementos sensíveis mais simples, irredutíveis, que se combinam e engendram os seres e fenômenos.

O tipo de explicação empirista, baseado em reuniões e acréscimos, cujo referencial é encontrado no próprio plano de fenômeno que deve ser explicado suscita contradições. Nesse gênero

Educ. e Filos., Uberlândia, v. 21, n. 42, p. 89-117, jul./dez. 2007. 
de explicação causal, uma mesma causa acarreta efeitos contrários e causas diferentes produzem o mesmo efeito. A contradição encetada pela ausência de um referencial que não está no mesmo plano dos fenômenos leva o Sócrates platônico a inverter o eixo em torno do qual pivota o conhecimento. Ao se deparar com a proposição de Anaxágoras segundo a qual o devir ocorre em função da "inteligência" e do "melhor", discerne que o conhecimento causal deve ser referenciado em um plano que ultrapassa a dimensão da physis. Explicar segundo uma causa é reportar os fenômenos a um referencial absoluto invariável e universal. Só a adoção de uma instância superior à physis elimina as contradições nas explicações e permite o conhecimento dos fenômenos naturais, pois conhecer é conhecer as causas. Algo é causa de outra coisa quando a ocorrência desta última segue, infalivelmente, após a primeira. $\mathrm{O}$ adjetivo aítios seguido de um genitivo significa "responsável por". Apontar a causa (aítion) de X é designar o que é responsável por $X$, da mesma maneira que uma corte determina que alguém é responsável por um crime. "Causa" e designação de responsabilidade é, originalmente, correlativa de determinação de um agente cuja ação acarreta algo infalivelmente. Nesse sentido, a determinação da causa propicia a inteligibilidade do fenômeno.

O empirismo dos fisiólogos, ao apontar para elementos materiais como causa, limita-se às condições necessárias dos fenômenos. A inteligibilidade mediante princípios, que determinam as condições de possibilidade dos fenômenos, requer um método que referencia os fenômenos a uma instância universal e absoluta. O novo método epistemológico empreende, então, uma "segunda navegação" em busca das causas. Seu ponto de partida é justamente a postulação da existência das Formas como referencial absoluto e princípio de cognoscibilidade. $\mathrm{O}$ método propõe a hipótese geral de que uma Forma " $F$ " é causa de todos os seres que possuem a propriedade "F-idade". Há, todavia, uma distinção conceptual entre ousia, eidos e idea (DIXSAUT, 2000, 479-500). Eidos designa aquilo que, mediante participação, nomeia as coisas sujeitas à geração e corrupção e delimita o problema da predicação: 
aquilo em relação ao qual as coisas devem ser relacionadas de modo a ser o que são. Trata-se de uma relação da physis com a esfera da qual advêm as causas de determinação de todas as coisas. Relação de determinação causal que indica primazia do ser, das Formas, em relação à physis. Ousia diz respeito à alma pensante, à passagem do devir para o atemporal, à insuficiência sensível em relação ao paradigma do "que é", à aspiração ao modelo indicado pela concepção, no âmago da alma, de um modo de ser que delimita o itinerário de um logos que é obra do desejo do filósofo. A ousia anuncia a Forma. Não se trata de um sujeito transcendental, condição de possibilidade do conhecimento, "consciência" de um "eu penso", mas de libertação do devir, purificação do sensível, iniciação, insuficiência e aspiração da alma a ser em si e às "coisas em si mesmas", mediante o esforço de um exame discursivo. A dialética não anuncia a transcendentalidade. Eidos, por sua vez, diz respeito a princípio de causalidade e à participação, relação predicativa de coisas físicas que determinam suas propriedades no devir e permitem a correta nomeação. A Forma justifica o nome e a predicação de coisas que estão no âmbito do devir. Mediante a participação, ela é causa da denominação e da predicação e confere estrutura à physis de molde a permitir um discurso não contraditório acerca do que está em devir. A Forma concilia o Logos com o devir e permite que este possa ser dito sem contradição, ela regra a contradição do devir, os ciclos de contrários, e injunge a exclusão da coexistência de princípios contraditórios no mesmo tempo e na mesma coisa. A Forma concilia o atemporal com o cronológico. Todavia, essa exclusão é apenas relativa, pois a participação limita a alteração da multiplicidade da physis. As coisas que são estruturadas essencialmente segundo uma Forma que possui um contrário indireto não podem admitir esse contrário sem deixar de ser elas mesmas. A alma possui um contrário que a exclui, não pelo que ela é em si, mas pela exclusão de contrariedade indireta entre Formas, porque ela infunde vida em tudo aquilo com que se associa. A vida estrutura a alma essencialmente, por isso, a alma é imortal. Estruturando essencialmente a physis, as Formas limitam a mudança continuada e impingem a exclusão de

Educ. e Filos., Uberlândia, v. 21, n. 42, p. 89-117, jul./dez. 2007. 
propriedades contraditórias. Com isso, as Formas são princípio de inteligibilidade, pois, como causas, determinam as coisas.

Idea se reporta ao logos que discorre sobre os contrários indiretos. Ela não é uma propriedade P que a Forma impõe sobre uma coisa particular, mas está vinculada sobretudo a ações designadas por verbos. Idea, por conseguinte, pressupõe o plano lingüístico e constitui a ação de estruturação das eidê que determinam as coisas: ela é a Forma aplicada às coisas, que faz com que elas tenham sua própria idéia e sejam exprimíveis por um logos que designa as ações de determinação e "informação" que age sobre elas. A idea, discursivamente, testemunha a natureza conquistadora e possessora da participação de algo na Forma que lhe determina. A physis só existe em função da participação e a idea é um índice de sobredeterminação essencial de algo por uma Forma que exclui a noção contrária e indica o poder das Formas de estruturar essencialmente as coisas de maneira a excluir noções contrárias e excluir as mudanças do devir. A idea manifesta a conformação da coisa à Forma e constitui o elo de ligação entre ambas, a conformação particular de cada coisa à sua Forma determinante. A injunção de uma Forma imutável sobre a coisa impede a continuidade do processo de mudança indefinida. A idea exclui o processo e a mudança. A idea torna manifesto aquilo que sofre a ação de causalidade da Forma e faz com que algo seja sua obra, ao mesmo tempo, conhecível e dizível.

A hipótese causal que recorre ao referencial absoluto das Formas muda o eixo epistêmico dos elementos particulares para a inteligibilidade. A causalidade baseada nas Formas implica o regramento do plano dos fenômenos pelas condições impostas por princípios de inteligibilidade e faz com que qualquer explicação da physis dependa de uma inteligência. A explicação pela participação nas Formas é análoga à relação do produto com um paradigma e, por isso, o fulcro da causalidade platônica é simultaneamente paradigmático e teleológico. 


\section{II - A epistemologia da "linha"}

A metáfora da "Linha" (República 510a ss) estabelece que a diânoia é a atividade de uma alma que se reporta ao inteligível mediante imagens. A diânoia visa ao inteligível, mas vem após os dois estados intermediários da doxa. As divisões da linha são operadas a partir da distinção entre imagens e os seus modelos originais. As coisas sensíveis possuem o duplo estatuto de serem capazes de projetar suas imagens e de servir como imagens que remetem para realidades inteligíveis, que só são atingíveis por hipóteses interpostas. A imagem está para o modelo, assim como a opinião está para o saber. Há quatro estados da alma correspondentes a cada uma das seções da Linha: no mais baixo a alma só se serve de imagens e no mais elevado ela não se vale de nenhuma imagem. Entre esses dois extremos, a conjectura e a intelecção, há dois estados intermediários em que a alma se vale de imagens. O que ela não apreende com clareza nas imagens gera a convicção, pistis. O que a alma apreende como imagens de um modelo original inteligível é a diânoia. A Linha configura uma metáfora para exprimir uma única atividade pensante e suas divisões correspondem a estados da alma e ao modo como esta adquire o conhecimento (DIXSAUT, 1996, p. 12). A Linha não é dividida em função da natureza dos objetos, mas em função de estados da alma nos quais ela trava contato com imagens e modelos originais. Não se trata, portanto, de uma hierarquia de ciências, mas do estabelecimento do modo como o conhecimento é construído numa psykhé pensante. No estado de conjectura, a alma só tem percepções confusas e apreende apenas reflexos e sombras. A diânoia se articula com a convicção e com a epistéme, mas a diânoia possui em comum com a conjectura o fato de que ambas não podem apreender seus objetos a não ser mediante imagens. Ambas sofrem de uma deficiência: a conjectura é privada da percepção do objeto e a diânoia, ao lidar com hipóteses, é privada da inteligência do princípio. A parte inferior da Linha indica um estado da alma que a remete para a percepção. Do mesmo modo que a conjectura não assegura a percepção do objeto, a diânoia

Educ. e Filos., Uberlândia, v. 21, n. 42, p. 89-117, jul./dez. 2007. 
não assegura a inteligibilidade operada pelas hipóteses. Mas o pensamento não se torna dialético enquanto não possuir o poder de se afastar das imagens. Os estados da alma representados na Linha indicam um único movimento do pensamento em momentos diversos até a completa intelecção. As imagens constituem o único modo de ligar o sensível ao inteligível. No ponto mais baixo, a alma possui somente a incerteza e é levada a um estado de oscilação que redunda numa afirmação irracional. Uma percepção clara do objeto, como um contato, uma visão, faz a alma passar da conjectura para a convicção. A reflexão e o tratamento intelectual das imagens as tornam figurações e remetem para realidades apenas inteligíveis. A intelecção culmina um processo e um continuum único que caracteriza o pensamento e o conhecimento. Esse pensamento é único, assim como a Linha é única, e está relacionado a estados da alma que denunciam o grau de apreensão do objeto e do conhecimento. A diânoia envolve o método hipotético e a derivação de conseqüências e verificação de coerência entre as proposições derivadas, sem ascender ao conhecimento dos princípios. A epistéme resulta da apreensão de um princípio mediante o questionamento. A ciência mais elevada é a dialética, que opera questões e extrai conseqüências de proposições até que haja a intelecção dos princípios.

A metáfora da Linha afirma o primado da inteligência sobre o objeto. Ela se refere a estados da alma e a parte da alma aparentada ao inteligível é a inteligência e é a inteligência, por sua vez, que engendra a intelecção. Isso significa que, para Platão, a mais alta ciência, a dialética, é um apanágio de uma alma que investiga segundo certa maneira e que o objeto não pode ser apreendido senão pela intelecção propiciada por um páthos da alma.

\section{III - A epistemologia cosmológica das leis}

O livro X das Leis desenvolve uma argumentação que explicita o vínculo e o papel constitutivo que a crença nos deuses e a religião cívica exercem na constituição das leis e na própria integração social da Polis grega, como um todo. A natureza do problema é 
posta, inicialmente, pelo modo como serão instituídas as leis que tratam da impiedade. Numa primeira aproximação, é abordada a necessidade de as leis serem fundamentadas na idéia de Justiça. Para serem justas, as leis devem basear-se não somente em sanções positivas, expressas em punições prescritas para os crimes de impiedade, mas, em vez disso, o legislador deve empregar todos os recursos possíveis para persuadir os infratores de que o princípio basilar das leis é a racionalidade. Racionalidade que espelha a virtude da Justiça e, por conseguinte, a racionalidade do melhor e do Bem para a Polis. Isso implica que, para Platão, a constituição legal da Polis não pode estar calcada apenas no seu aspecto coercitivo e na injunção das penas previstas para os crimes, mas deve, sobretudo, ser fundamentada no assentimento ao caráter racional que constitui a elaboração das leis. É a racionalidade essencial das leis que garante a universalidade absoluta da Justiça como princípio político formador da sociedade. Para o estabelecimento dessa fundamentação, Platão começa por demarcar uma separação dos âmbitos tradicionais de persuasão veiculados pela narrativa mítica e por um gênero de persuasão que, a princípio, deve dar primazia à racionalidade argumentativa. Os destinatários desse discurso persuasivo são cidadãos ímpios insensíveis à eficácia da narrativa mítica (Leis X 885 c-e).

Os mitos possuem um caráter enciclopédico que tece a trama do tecido cultural da Polis - inextricavelmente associado à crença nos deuses. A potência eficaz do mito sobre os afetos e sua ação arrebatadora sobre as paixões decorre da encantação (BRISSON, 1994, p. 93-113). O encanto mítico suscita alguns sentimentos e afasta outros, produz a piedade e purifica a alma de paixões destruidoras que influenciam a razão negativamente, especialmente o temor. Por essa razão, a narrativa mítica, em função de seu caráter de estoque cultural e eficácia sobre os afetos, configura o mais tradicional instrumento na paidéia do homem grego (Leis X 887 c-e).

Mas os ímpios tratados no livro $\mathrm{X}$ das Leis são descritos como renitentemente resistentes à encantação mítica. Nem a exemplaridade da formação infantil baseada nos mitos, nem a

Educ. e Filos., Uberlândia, v. 21, n. 42, p. 89-117, jul./dez. 2007. 
exemplaridade dos ritos e cultos, regularmente praticados pelos pais nas festas religiosas, nem o argumento da maioria de que, tanto gregos, como bárbaros, crêem nos deuses, é capaz de levar os mais obstinados à crença. Por isso, a especificidade dos destinatários condiciona o gênero de discurso que tem como visada a persuasão. Tal persuasão é imprescindível para o assentimento racional ao estabelecimento das leis, o que representa, em última instância, a fundamentação racional da própria noção de Justiça.

Em função da escolha deliberada de renunciar à eficácia mítica, o cerne da argumentação adotada por Platão recorre a um modelo cosmológico que serve de base para a explicitação dos princípios nos quais deve se basear a elaboração das leis (Leis X 886a).

A principal causa para a impiedade, segundo Platão, reside no espantoso argumento, sustentado engenhosamente por certos sábios, de que as causas de todas as coisas que existem, que existiram e que existirão, são a natureza, o acaso ou a arte. A impiedade é fruto da ignorância que se faz passar pela mais alta sabedoria, ou seja, de uma inversão na atribuição da causalidade da geração e corrupção de todas as coisas. Tais sábios qualificam como causa das maiores e mais belas coisas, a natureza e o acaso, e como causa das menores coisas, a arte, que apenas modela o que é recebido a partir das coisas maiores (Leis X 886 c-d). Em particular, as arkhai, identificadas com os quatro elementos cosmológicos - a água, o fogo, a terra e o ar - existem por natureza e são inteiramente privadas de vida. A partir de suas propriedades os quatro princípios dão origem às mais diversas combinações e, pelo acaso, formam todos os astros e corpos celestes. O arranjo do kósmos, segundo os mesmos sábios, não pressupõe uma inteligência divina ordenadora, mas ocorre segundo a alternância de potências opostas, como o quente e o frio, o seco e o úmido, o mole e o duro. Todo o kósmos origina-se do arranjo casual e da combinação aleatória dos contrários. Casualidade e potências sem vida configuram a esfera da natureza, que tomada como causa, propicia a impiedade. A arte, por outro lado, demarca o plano daquilo que é mortal. Ela mesma é mortal, inventada pelos mortais. Por ser derivada da natureza e do acaso, mera modelação secundária de 
princípios primeiros não gerados, a arte possui somente uma pequena parcela de verdade. Ela denota apenas um simulacro, como a pintura, ou a música e outras artes auxiliares, por isso, a arte possui pouca comunhão com a natureza, especialmente a política. A maior parte da política deriva da arte e, por conseguinte, toda a legislação não é obra da natureza, não comunga com a verdade: é o produto da contingência da situação (Leis X 889 a-e).

Essa concepção convencionalista da política implica que a crença nos deuses passa a ser uma invenção útil para a imposição de certas leis. As características particulares e consuetudinárias de cada povo exigem, para a imposição das leis, a necessidade do temor das conseqüências da infração. Daí a pertinência de deuses e de éthos peculiares a cada cidade, a cada povo. Os deuses existem na medida em que são meios de reforçar a imposição positiva das leis. Nesse sentido, a religião existe apenas para manter a força no âmbito da justiça. O mecanicismo de um kósmos sem vida implica, simultaneamente, o relativismo antropológico dos valores. A conseqüência final desse relativismo redunda no fato de que a justiça não existe por necessidade e natureza, ou seja, não existe de maneira universal e absoluta. Ao contrário, ela é fruto da opinião, sujeita a permanente contestação e mudanças segundo os ventos das circunstâncias. Se não há uma noção unívoca da justiça, tampouco pode haver valores imutáveis. A moral de situação, defendida por uma certa sofística, conduz à dominação pela força e pela violência e denota a lei do mais forte. Tais são as implicações implícitas na impiedade e na correspondente naturalização do kósmos (889e-890e).

O ponto originário de toda essa cadeia de concepções, que culmina no primado da força na política, pode ser identificado com o estabelecimento equivocado da causa primeira da geração e corrupção de todos os seres. O problema da impiedade e da legislação, conforme o desenvolvimento do argumento de Platão, corresponde ao problema da atribuição da causalidade dos princípios primeiros (891e). O que os sábios fisiólogos identificam como causas primeiras são, de fato, causas secundárias. Para Platão, a explicação do engano está no fato de que essa identificação

Educ. e Filos., Uberlândia, v. 21, n. 42, p. 89-117, jul./dez. 2007. 
das causas primeiras com os quatro princípios dos fisiólogos ignora inteiramente a natureza da alma e sua potência. A dynamis da alma consiste em ser a causa primeira das mudanças e do arranjo dos corpos. Isso ocorre, em virtude de a alma e, por conseguinte, todas as suas propriedades, existirem antes dos corpos. A opinião, a previdência, a inteligência, a arte e a lei são anteriores aos corpos. Isso significa que as mudanças ocorridas no processo de geração e corrupção de todos os seres são derivadas da instituição prévia de um ordenamento segundo uma inteligência. Significa, também, que todos os corpos e o kósmos, como um todo, existem por causa da inteligência, dynamis da alma. Em conseqüência, a alma é a condição de possibilidade do devir, de todas as mudanças e transformações, de todas as sucessões e processos, de todos os fluxos passíveis de ocorrerem na natureza. A natureza é posterior à arte e à inteligência (892a-c).

A inteligência é subjacente à natureza, aos processos de mudança, ao arranjo e ao devir dos corpos. A natureza é definida como a geração dos seres. Se for possível provar que a alma é mais velha que os corpos, pode-se, igualmente, estabelecer a inteligência e a racionalidade como causa primeira e condição de possibilidade da natureza e da geração dos seres. Dessa maneira, uma racionalidade subjacente ao kósmos depende da prova da anterioridade da alma em relação ao corpo.

Para levar essa prova a efeito, Platão, primeiramente, classifica todos os seres em dois gêneros: os que existem em repouso e aqueles que estão em movimento. Após isso, Platão discrimina hierarquicamente todas as formas de movimento, do menos perfeito ao mais ativo e superior (893b, ss). Há dois tipos principais de movimento: o que é capaz de mover outros corpos e é incapaz de mover a si mesmo; e o que é capaz de mover outros corpos e a si mesmo. Da interação dos choques entre os corpos, resultam divisões em outros corpos ou então agregação de um ao outro, ou, ainda, a extinção completa do movimento. Isso significa que da interação de corpos em movimento, resulta a geração ou corrupção de novos corpos, ou a extinção ou geração de novos movimentos. $\mathrm{O}$ modelo dinâmico dos corpos em movimento implica a 
equivalência das noções de movimento, mudança, geração e corrupção, todos ocorrendo no plano do devir. De todos os movimentos, o mais ativo, o mais forte é aquele capaz de mover a si mesmo (894e).

Toda mudança consiste num processo que se situa no plano do devir e, como tal, é um movimento. Todo movimento comunicado pressupõe um movimento primeiro, causa de toda a seqüência encadeada das mudanças. Esse primeiro movimento, causa de todos os demais, é o que causa a si mesmo. Se todas as coisas existissem num permanente estado de repouso e ausência de mudança, só haveria movimento a partir do que tivesse a potência de causar a si mesmo. Por isso, pode-se afirmar que em todo processo de mudança, o que é mais antigo é o que causa a si mesmo e desencadeia todas as demais mudanças. Se um movimento dessa natureza, que é causa de si mesmo, é produzido em algo constituído pelos princípios dos fisiólogos, ou seja, coisas terrestres, aquosas, ígneas, simples ou compostas, essa coisa é dita viva.

Ademais, o conhecimento de algo ocorre mediante sua essência, que é dada, ou pelo nome, ou pela definição (895d). Pode-se conhecer algo mediante uma definição para um nome, ou atribuindo-se um nome para uma determinada definição. Como todos os seres vivos são reconhecidos como tal porque possuem alma, a definição para o nome "alma" deverá ser: "a essência que é capaz de mover a si mesma". Por ser princípio primeiro de movimento e, ao mesmo tempo, princípio e causa da vida, a alma também é a causa e o princípio primeiro da geração e corrupção de todos os seres, dos passados, dos presentes e dos que estão por vir. Ela é a causa das mudanças e transformações que configuram o devir da natureza.

Como princípio primeiro do movimento e do devir, a alma é o mais antigo dos seres (896 a-c). Os seres que recebem passivamente o movimento de outros não têm alma, ou seja, não têm vida. Em conseqüência, a alma existe antes do corpo e o corpo só existe posteriormente à alma e se submete à sua ação. Isso implica ainda, que as propriedades da alma existem antes das propriedades dos corpos. Os caracteres, os costumes, as vontades, os raciocínios, as

Educ. e Filos., Uberlândia, v. 21, n. 42, p. 89-117, jul./dez. 2007. 
opiniões verdadeiras, a previdência e a memória existem antes da extensão, da largura e profundidade dos corpos, porque a própria alma existe antes dos corpos. É ela que determina o seu devir.

Como causa de todas os processos, a alma é causa tanto dos bens, quanto dos males, do justo e do injusto. Por isso, Platão postula a existência de ao menos dois tipos de alma; a que produz o bem e aquela que é capaz de fazer o contrário. Além disso, se a alma é o princípio que governa todos os seres, ela deve, também, dirigir os movimentos celestes. Todos os seres e toda a natureza são governados por uma alma que se junta à inteligência para governar, com sabedoria, segundo o melhor. Se a alma a tudo governa segundo uma inteligência que determina o melhor, a marcha e as revoluções celestes correspondem à revolução e aos raciocínios da inteligência. Há uma homologia entre o gênero de princípios que governam os movimentos das esferas celestes e os movimentos da alma. Os princípios diretivos do kósmos ocorrem segundo o melhor e isso implica que a sua ordenação é o resultado de uma inteligência que lhe é subjacente. Essa ordenação pressupõe uma regularidade que se estende, estruturalmente, a todos os seres e a todas as propriedades ordenadas segundo o melhor (896d 897a).

Dentre todos os movimentos, o mais perfeito e o que revela mais inteligência é, justamente, o movimento circular que reproduz, de uma mesma maneira, as mesmas regras e que transmite, proporcionalmente, o movimento de todas as partes do raio do círculo até o centro. Essa regularidade universal é a característica propiciada pela inteligência que subjaz tanto à ordenação cosmológica, quanto à ordenação da Polis, produzida por leis elaboradas racionalmente. A ausência de regras, de proporção, e de ordem, são análogos à imprudência e à infração das leis (898b).

Por isso, a racionalidade, subjacente à regularidade das leis do kósmos, constitui o paradigma e o arquétipo para a ordenação perfeita das leis da Polis. Tal racionalidade não pode ser apreendida senão pela inteligência. A conexão entre regularidade universal e inteligibilidade confere a racionalidade que deve fundamentar a 
justiça na constituição da Polis. Tal conexão representa um desdobramento das idéias pitagóricas que afirmam que há uma ordem matemática, divina, baseada nas proporções numéricas da música, e que rege os movimentos celestes. A noção de uma harmonia cósmica expressada em termos de razões numéricas e numa música astral constitui uma das idéias mais frutíferas oriundas do pitagorismo. A identificação da inteligibilidade e a tentativa de explicação do kósmos em termos matemáticos constitutivos de uma harmonia das esferas é a pedra angular da noção de que uma ordem regrada perpassa, ao mesmo tempo, a cosmogonia e a constituição das leis da Polis.

No argumento dirigido a destinatários refratários à formação tradicional, que são adeptos de uma cosmogonia irracional, Platão não recorre às noções de um demiurgo que modela o kósmos em consonância com as Formas imutáveis. Mas parte de concepções peculiares aos fisiólogos, como o movimento, o repouso, a geração e corrupção dos seres, para demonstrar que os aspectos sensíveis do mundo só podem ser explicados mediante a inteligibilidade de regras ordenadoras que possibilitam a sua existência. A inteligência, diz Platão, é uma deusa que a tudo governa com sabedoria segundo o Bem. A harmonia celestial é correspondente à harmonia da alma, porque, segundo os pitagóricos, a alma e todo o céu são harmonia e número. A inteligibilidade das regras que governam o kósmos permite a transposição da ordem cosmológica para o plano político. A fundamentação das leis e da justiça requer a inteligibilidade da racionalidade que as estrutura. Racionalidade que é homóloga àquela que preside a perfeição dos movimentos celestes.

Essa fundamentação racional do plano político empreendida no livro $X$ das Leis forja o aparecimento de um quadro mental que seria prenhe de desdobramentos na história da Filosofia. A racionalidade cosmológica e a correspondente universalidade da noção de justiça, a afirmação de valores permanentes e imutáveis, só é factível mediante a existência consentânea de uma psykhé e de uma inteligência. A anterioridade da alma em relação ao kósmos é, mais uma vez, de ordem ontológica e epistemológica. Sua afirmação equivale a afirmar que o centro epistêmico do

Educ. e Filos., Uberlândia, v. 21, n. 42, p. 89-117, jul./dez. 2007. 
conhecimento é encontrado na psykhé e não nos elementos particulares que configuram os fenômenos.

\section{IV - A demiurgia no timeu}

Segundo Luc Brisson (2001, p. 21 ss.), a ordenação causal se instaura no kósmos pela atividade "fabricadora" de um deus artesão que regra o plano das coisas sensíveis. Esse deus é essencialmente bom, e por ser bom é racional, é uma inteligência que ordena todas as coisas segundo o paradigma do bem. Platão identifica a bondade com a racionalidade e, por essa razão, a melhor ordenação do universo pressupõe a primazia ontológica da inteligência sobre as coisas sensíveis. Porque é uma inteligência, o demiurgo raciocina, calcula, reflete e "leva em consideração", ajuíza sobre aquilo que produz (30a ss). Além disso, o demiurgo delibera segundo uma vontade, ele escolhe e possui afetos (37c). O demiurgo configura uma personificação da função produtora do universo. A atividade demiúrgica caracteriza-se por ser de ordem artesanal e fabricadora, em vez do engendramento e filiação que caracterizam os deuses tradicionais. O demiurgo é, sobretudo, um construtor cuja ação se assemelha às atividades metalúrgicas (35a) que forjam ligas metálicas: ele molda, conecta e modela as placas que constituem os círculos celestes. Sua principal atividade consiste em estabelecer conexões segundo proporções entre os elementos constituintes do corpo e da alma do mundo. O demiurgo se comporta, também, como pintor ao dispor aos astros no céu e como oleiro e modelador de cera, quando fabrica o homem. Além disso, ele se comporta como camponês, ao semear as almas e como fundador de cidades quando arranja as partes da alma. O demiurgo transfere sua potência intelectiva para a alma do mundo, que dá continuidade à sua atividade ordenadora. Essa ordenação é feita segundo o modelo de um paradigma sobre um material, a khóra, desordenado e resistente ao arranjo promovido pela inteligência. A ordenação segundo uma inteligência ocorre no aión, na eternidade atemporal (37c), em que a alma do mundo é fabricada. Só após a fabricação da alma do mundo, os astros e os movimentos celestes são 
fabricados, dando origem ao número que delimitará o tempo cronológico. Por essa razão, em função da ordenação reportar-se a uma inteligência atemporal, a crítica de Aristóteles que separa processo artesanal, de processo natural (Fís. VIII, 251b), só tem sentido no âmbito do tempo cronológico. Daí a diferença fundamental entre epistemologias diametralmente opostas. Os processos naturais aristotélicos apresentam uma ordenação intrínseca imanente que é finalista. A atividade produtora demiúrgica, ao contrário, pressupõe uma inteligência ordenadora que interfere na physis promovendo sua ordenação segundo o paradigma do melhor e do bem. Um modelo é teleológico e o outro é paradigmático. A atividade demiúrgica é, ademais, pontual: após fabricar a alma e o corpo, ele se retira e transfere a função ordenadora para a alma. Por essa razão, a alma possui completa autonomia em relação ao plano sensível. O conhecimento envolve o concurso das Formas universais e imutáveis; as coisas sensíveis que são imagens da Formas decorrentes da ação determinadora imprimida no material, e o material cuja característica é o caos e a resistência à ação conquistadora das Formas.

A alma é definida como princípio do movimento, mas por possuir uma estrutura matemática, confere aos seres vivos certa regularidade no comportamento e, nos homens, uma conduta coerente segundo princípios de ação. A regularidade dos seres vivos é análoga às regularidades cosmológicas e, por isso, o mundo é vivo e a estrutura matemática de sua alma confere a ordenação matemática do universo. A alma é intermediária entre as Formas e as coisas sensíveis e embora seja constituída pelos mesmos elementos estruturais das coisas sensíveis, o "Ser", o "Mesmo" e o "Outro", ela é uma entidade imaterial que possui a característica de intervir no plano sensível e guarda a faculdade da inteligência. A alma do mundo é o princípio das mudanças ordenadas do kósmos e é responsável pelos movimentos e revoluções celestes de acordo com um regramento matemático. Dessa maneira, os traços distintivos da alma são a sua faculdade cognitiva e voluntarista e sua função de princípio do movimento. Além disso, a alma é transmissora do regramento matemático e responsável pela

Educ. e Filos., Uberlândia, v. 21, n. 42, p. 89-117, jul./dez. 2007. 
ordenação cósmica. A parte imortal da alma humana é sucedânea da alma do mundo e possui as mesmas faculdades e funções. Ela possui primazia ontológica sobre as coisas sensíveis e sua faculdade distintiva é a cognição. Mas além da parte forjada pelo demiurgo a alma humana possui uma parte desejante e outra agressiva que permitem sua interação com as coisas sensíveis.

A atividade demiúrgica, herdada pela alma humana, denota o seu poder causal. Essa atividade implica uma mestria sobre a obra fabricada que faz referência a um paradigma exterior e superior. Esse paradigma é o referencial absoluto para a aquisição de todo conhecimento e permite a construção da obra com a reprodução das virtudes do modelo. Isso significa que a cognoscibilidade é determinada por princípios eternos universais extrínsecos aos objetos. A operação demiúrgica é, ao mesmo tempo, um trabalho e uma construção causal e geométrica. Seu modus operandi é o dianoiético, que partindo de princípios matemáticos inteligíveis, articula e conecta sua obra segundo um método geométrico. A demiurgia evidencia o fato de que a epistemologia platônica parte de princípios causais universais que pressupõem uma faculdade ao mesmo tempo cognitiva e fabricadora.

\section{V - Conclusão}

A questão das virtudes, nos diálogos platônicos, suscita a necessidade de um paradigma absoluto que sirva de norma e modelo, critério de aquilatação da práxis. A necessidade de um padrão absoluto no plano das virtudes engendra o problema do conhecimento e da possibilidade de se conhecer noções absolutas prévias e preexistentes ao plano das ações. Platão rejeita o procedimento dos fisiólogos que buscavam princípios explicativos no próprio plano dos fenômenos e empreende uma reviravolta, por ele chamada "segunda navegação", cujo resultado culmina na hipótese fundamental das Formas. Tal hipótese, tributária do método das hipóteses de Filolau de Crótona, consolida o axioma fundamental que enseja um modelo explanatório para a determinação essencial e para as interações entre todos os 
elementos particulares que compõem a phýsis. Tal modelo reúne um número mínimo de princípios - que unificam os problemas éticos aos problemas do conhecimento e os problemas epistemológicos a uma causalidade explanatória dos fenômenos físicos. A démarche dialética que culmina na epistéme configura-se a partir de uma axiomática inextricável de modos de inteligibilidade e do pressuposto fundamental de que os princípios prévios legisladores do kósmos exigem a inteligência como fulcro em torno do qual pivota o conhecimento.

\section{Referências}

PLATÃO. Les Lois. Tradução, introdução e notas por Luc Brisson. Paris: G.F. Flammarion 2006.

Phédon, Tradução, introdução e notas de Monique Dixsaut. Paris: G.F. Flammarion, 1991.

Tradução de P. Vicaire, introdução e notas de L. Robin. Paris: Les belles Lettres, 1995.

Timée, Crítias. Tradução, introdução e notas de Luc Brisson. Paris: GF Flamarion, 2001

A República. Lisboa: Fund. Calouste Gulbenkian, 1989.

ANNAS, Julia. Introduction à la République de Platon. Paris: VRIN, 1994.

BRISSON, Luc. Le Même et l'Autre dans la Structure Ontologique du Timée de Platon. Sankt Augustin: Academia Verlag, 1998.

. Platon, Les Mots et les Mythes. Paris: La Décourverte, 1994. . Puissance et Limites de la Raison. Paris: Les Belles Lettres, 1995.

Educ. e Filos., Uberlândia, v. 21, n. 42, p. 89-117, jul./dez. 2007. 
CHERNISS, Harold. L'économie philosophique de la théorie des idées. In: PRADEAU, Jean-François. Platon: Les Formes Inteligibles. Paris: P.U.F., 2001. p. 155 - 176.

DIXSAUT, Monique. Le Naturel Philosophe. Paris: VRIN, 2001.

Platon et la question de la Pensée. Paris: VRIN, 2000.

IGLÉSIAS, Maura. Platão: A Descoberta da Alma. Boletim do CPA, Campinas, n. 5/6, p. 13-58. 1988.

JOLY, Henri. Le Renversement Platonicien, Paris: VRIN, 1994.

KAHN, Charles, H. Pythagoras and the Pythagoreans. Indianapolis: Hackett Pub, 2001.

HUFFMAN, Carl. Philolaus of Croton. Cambridge: Cambridge U. Press, 1998.

PRADEAU, Jean-François. Platon: Les Formes Inteligibles. Paris: P.U.F., 2001.

ROW, Christopher.L'Argument par 'Affinité' dans le Phédon. Revue Philosophique de la France et de L'Étranger. Paris, n.4, p. 463-477. 1991.

WHITE, David. Myth and Metaphysics in Plato's Phaedo. Selinsgrove: Susquehanna University Press, 1989. 
